\title{
Regional Features of the Financial Literacy the Population of the Sverdlovsk Region
}

\author{
Elena Razumovskaia ${ }^{1,2, *}$, Denis Razumovskiy ${ }^{1,3}$, Elena Ovsyannikova ${ }^{1}$ \\ ${ }^{1}$ Ural State Economics University, 620144 Yekaterinburg, Russia \\ ${ }^{2}$ Ural Federal University, 620002 Yekaterinburg, Russia \\ ${ }^{3}$ Russian Academy of National Economy and Public Administration under the President of the \\ Russian Federation (UIU RANEPA), 620144 Yekaterinburg, Russia
}

\begin{abstract}
The presented research is devoted to analysis of the principles and optimality criteria for the structure of household financial resources, formed on the basis of surveys of a sample of 5,842 respondents from the Sverdlovsk region based on the author's methodology for assessing the level of financial literacy and the structure of citizens expenses. The initial hypothesis about the influence of the level of financial literacy of the population on the structure of household spending has been verified. Examples of author questionnaires are presented, developed taking into account the methodological support of the Central Bank of the Russian Federation and the NAFR Analytical Centre. The conclusion is substantiated that more financially literate people are inclined to plan income and expenses and are able to evaluate the structure of their expenses from the position of optimality. The study is supplemented by an analysis of an array of statistical information on indicators of the financial situation of the population of the cities of the Sverdlovsk region. The purpose of the study is to verify the relationship between the level of financial literacy of the population of the Sverdlovsk region and the structure of household spending based on a subjective assessment of optimality by respondents. General methodology of this study is a sociological survey, which adapted by the authors from the methods of the Central Bank of Russian Federation and OECD countries for the conditions of the Sverdlovsk region. The scientific message is interfaced with the model of J. Nash. Main results of this research is: 1) the hypothesis about the influence of the level of financial literacy of the population on the optimality of the structure of household spending is substantiated; 2) author principles and optimality criteria for the structure of household financial resources based on cost structure have been developed.
\end{abstract}

\section{Introduction}

The most difficult thing when conducting research in the field of assessing the optimality of the structure of financial resources of households is the development of criteria for optimality. Indeed, what is the optimality when it comes to people's preferences for using disposable

\footnotetext{
*Corresponding author: rasumovskaya.pochta@gmail.com
} 
income? The answer, obviously, is to look for in a different formulation of the problem - a kind of averaging, not «according to the detailed», but a consolidated structure of expenses. The authors' approach is based on the basic concepts of financial and economic science. So, relying on the well-known «A. Maslow's pyramid», we can confidently assert that all rational financial decisions, without exception, are made according to the principles of optimality from the position of consistently meeting needs: from the need for security to self-realization. The pyramid concept provides a basis for the formation of a logical structure in relation to the optimal structure of household finances, at this stage - only in relation to expenditures. The authors are convinced that the awareness of the need to optimize the structure of financial resources and the development of a habit of adhering to financial discipline in managing disposable income can contribute to the formation among the population of an understanding of (in) sufficiency of income and interpretation of the state of their budget as not balanced. Further, the stage of making decisions will inevitably come either in favour of reducing costs, or in favour of finding a higher income and diversifying its sources. In essence, this message can further serve as a justification for optimality criteria not only based on the structure of costs, but also on the application of elements of game theory. The authors consider it expedient in this case to rely on the provisions of the equilibrium theory of J. Nash, which is due to several important aspects that are of fundamental importance for achieving the goal of this study: 1) the rationality of decisions made in relation to the disposal of income; 2) the sufficiency of ideas about the conditions in which the named decisions are made and implemented; 3) the profiles of behaviour strategies in relation to achieving the optimal structure of financial resources of households by the respondents are reasonable from an intuitive point of view; 4) the dynamism of modelling to optimize the structure of financial resources of households over time.

The position, which, according to the authors, is very controversial is the awareness of the positions and strategic intentions of the participants in financial relations and their mutual dependence. This provision, inherent in the theory of J. Nash, determines the actions of the participants in the model, provided that none of them can change their decision until the other participants have changed theirs [5]. With regard to the formation of strategies that are implemented by a group of certain participants and that perform certain actions by the model - for example, an investment project - the provision of awareness and dependence is logical; when we are talking about an indefinite set of participants in an indefinite number of relationships - as in this case - then, probably, we can talk about the conditionality of the actions of households only to the extent that they are free to make and implement their financial decisions [7]. At the same time, it makes no sense to say the same about other subjects of such relations - the state and employers, whose actions are not conditioned and do not depend on the actions of the population. Assuming that this provision is simplified to the predictability of such actions, an attempt can be made to create a model of household behaviour to optimize the structure of financial resources, which would become more or less realistic. Achievement of optimization of the structure of financial resources can be based on the equilibrium according to J. Nash based on the condition of the model, according to which it is unprofitable for any of the participants in the relationship to deviate from a certain strategy if the others fulfil their obligations. This condition is fundamental in the concept of equilibrium by J. Nash and can only be welcomed in all practically implemented agreements. Coercion to fulfil obviously unfavourable conditions of one of the parties also does not fit into the concept of equilibrium by J. Nash, which cannot but be positively assessed for the purpose of forming a mechanism for optimizing the structure of financial resources of households. Strictly speaking, such coercion does not exist - within the limits of disposable income, people are free to dispose of their financial resources, but at the same time, there are risks associated with a wide range of people's needs [6]. The requirement to level the risks of poverty can be (and is) fulfilled on the basis of V. Pareto's equilibrium: distribution occurs, 
in which the welfare of each of the parties (in this case, members of society) can be increased only if the welfare of the other party decreases. In this case, the question of optimization is not resolved at all. Based on the potential application of J. Nash's optimality, the authors have chosen a research method that presupposes, at the initial stage, a subjective assessment by respondents of the optimality of the structure of their financial resources and factors that impede the achievement of optimality [8]. In fact, the authors use the same research methods in this thematic area as a number of modern foreign researchers based on so far simple applied aspects - increasing the level of financial literacy of the poor, attracting the population to the financial market, developing a propensity for financial discipline, and a number of others [2, 3]. One way or another, serious researchers come to the conclusion about the relationship between the level of development of society and the quality of life of the population; the need for financial planning in households and the formation of savings; about inequality deepening as a result of the growing credit burden of the population and financial instability [9].

\section{Research methodology}

Traditionally, surveys are the main method of research on identifying and analysing household decisions, since it is extremely difficult to collect and process statistical information in a narrow direction, it takes a long time, and in some cases it isn't possible. It is possible to objectively determine the structure of financial resources of the households using data from commercial banks, employing companies, and official statistics. Some of this data is not subject to disclosure, since there is legislation regarding the protection of personal data; part - may not be reliable enough; some may refer to non-respondents. Therefore, the authors decided to collect information about the structure of financial resources of the rrespondents based on the voluntarily provided information by the latter. Conducting surveys is associated with the observance of the rules stipulating the need to obtain complete, if possible - reliable and objective information. Enragedly, the rules for conducting surveys are as follows: In world practice, in order to obtain reliable and relevant data of research value, surveys are used, the methods of which are usually typified according to a number of criteria:

- by the method of obtaining data:

- contact - interviewing;

- contactless - questioning;

- by the form of holding:

- oral - by phone, recording on audio devices;

- written - filling out formalized questionnaires;

- at the venue:

- solid - in crowded places with high traffic (shopping centres, crowded events, transport hubs, etc.;

- electoral - according to the meta of study, work, residence;

- by the level of competence:

- massive - continuous polls;

- expert - the audience selected by the research topic;

- by the way of interacting with respondents:

- personal (face-to-face);

- impersonal (correspondence).

When conducting surveys, it is important to comply with the rules, which is due to the need to obtain as complete information as possible, if possible - reliable:

- Topics of the survey. The survey should be about one topic. The inclusion of several thematic areas in the survey will not allow obtaining objective information: the answers of 
the respondents will be incomplete. Switching from one topic to another will reduce the reliability, which is already not quite inherent in this research method.

- The optimal structure of the questionnaire. The wording of the questions should be short, understandable, not numerous, suggest an unambiguous answer; the number of questions should be such, the time of interviewing or filling out the questionnaire did not exceed $5-7$ minutes.

- Logical design of the questionnaire. The sequence of questions should be built in such a way that they are not only related, but also keep the respondent's interest: first, simple questions should be placed, then more complex ones, but not so much as to confuse; at the end - again simple ones, in order to leave the impression of feasibility, potential surmount ability of the task.

- Target audience of the survey. The correct choice of the target audience contributes to the collection of reliable information, since it is unlikely to be equally distorted by an informed (dedicated) audience. Therefore, the sample of respondents must meet certain criteria: demographic, social, cultural and others that are relevant to the topic of the survey.

The authors conducted a survey consisting of two thematic blocks (questionnaires):

- by assessing the level of financial literacy of the population by filling out questionnaires in person;

- according to the respondents' assessment of the optimality of their financial resources in terms of the structure of expenses.

\section{Research results}

The experience of conducting a unique pilot survey in this format has already yielded tangible positive results - it was possible to obtain primary data showing the respondents' assessments of the structure of their financial resources from the standpoint of optimality (Table 1).

Table 1. Questionnaire questions to assess the optimality of financial resources by respondents $[10$, 11]

\begin{tabular}{|l|l|}
\hline \multicolumn{1}{|c|}{ Questionnaire questions } & \multicolumn{1}{c|}{ Answer options } \\
\hline $\begin{array}{l}\text { 1. Do you think that your } \\
\text { financial resources (income, } \\
\text { expenses) require monitoring } \\
\text { for optimum: }\end{array}$ & $\begin{array}{l}\text { - yes, of course; } \\
\text { - no, I don't think so; } \\
\text { - I find it difficult to answer. }\end{array}$ \\
\hline $\begin{array}{l}\text { 2. Do you agree that your } \\
\text { financial resources can be } \\
\text { optimal if: }\end{array}$ & $\begin{array}{l}\text { - if your family has no debt obligations; } \\
\text { - if your family has the opportunity to form savings, } \\
\text { investments; } \\
\text { - if your family's expenses do not depend on income; } \\
\text { - if I find it difficult to answer. }\end{array}$ \\
\hline $\begin{array}{l}\text { 3. Is it possible to consider that } \\
\text { your financial resources have } \\
\text { an optimal structure if: }\end{array}$ & $\begin{array}{l}\text { - expenses for current consumption do not exceed 50\%; } \\
\text { - servicing of debt obligations does not exceed 30\%; } \\
\text { - Your family generates savings in the amount of about } \\
10 \% \text { of income; } \\
\text { - Your family spends about 10\% of their income on } \\
\text { education and medical examinations; } \\
\text { - Your family uses loans for current consumption; } \\
\text { - I find it difficult to answer. }\end{array}$ \\
\hline $\begin{array}{l}\text { D. Do you consider it } \\
\text { appropriate to: }\end{array}$ & $\begin{array}{l}\text { - have a diversified income? } \\
\text { - to plan expenses for perspective intervals of time? - } \\
\text { keep track of income and expenses? } \\
\text { - bear the costs of developing yourself and your family } \\
\text { members? }\end{array}$ \\
\hline
\end{tabular}




\begin{tabular}{|l|l|}
\hline & $\begin{array}{l}\text { - use your income at your own discretion based on the } \\
\text { principle of «one life»? } \\
\text { - is it necessary to participate in charity, following the } \\
\text { principle of «help your neighbor»? } \\
\text { - I find it difficult to answer. }\end{array}$ \\
\hline $\begin{array}{l}\text { 5. Do you think that the state, } \\
\text { the employing company or } \\
\text { financial institutions should } \\
\text { help you if: }\end{array}$ & $\begin{array}{l}\text { - your expenses exceeded your income; } \\
\text { - you have nothing to pay for your loan obligations; } \\
\text { consumption in case of loss of work; } \\
\text { - nobody owes me anything, this is my area of } \\
\text { responsibility; } \\
\text { - I find it difficult to answer. }\end{array}$ \\
\hline
\end{tabular}

Characteristics such as age, gender of the respondents, availability of savings (and / or assets), level of income and education were also recorded and form the basis for the next stages of analysis and detailed interpretation of the results of the study. The importance of a wide range of characteristics of survey participants is determined by the fact that the results obtained serve the purpose of predicting trends in the financial behaviour of the population during periods of price and devaluation shocks, the formation of financial education programs based on target channels - schools, middle and higher educational institutions, corporate structures, pension funds, etc. institutions of social orientation.

The authors proposed the principles of optimality of financial resources of households:

- the principle of sufficiency of current consumption;

- the principle of covering debt obligations;

- the principle of compulsory savings;

and criteria of critical optimality ( $\%$ of disposable income):

- current consumption up to $50 \%$ (including food, clothing, utility bills and communications);

- debt obligations up to $30 \%$;

- savings of at least $10 \%$;

- development (education, medicine) at least 10\%.

The principles and criteria reflect the logic of financial discipline, therefore, a questionnaire was formed on their basis.

The processed survey results are presented in Table 2 - the respondents are pre-clustered by the level of financial literacy based on the questionnaire survey according to the adapted methodology of the Central Bank of the Russian Federation and the Analytical Centre National Agency for Financial Research (Table 2).

Table 2. Data on the respondents' assessment of the optimality of financial resources

\begin{tabular}{|l|c|c|c|c|c|c|c|}
\hline \multicolumn{1}{|c|}{$\begin{array}{c}\text { Groups / } \\
\text { Result }\end{array}$} & $\begin{array}{c}\text { Number, } \\
\text { people }\end{array}$ & $\mathbf{1}$ & $\mathbf{2}$ & $\mathbf{3}$ & $\mathbf{4}$ & $\mathbf{5}$ & $\begin{array}{c}\text { Averidge } \\
\text { means, \% }\end{array}$ \\
\hline $\begin{array}{l}\text { Financially } \\
\text { literate }\end{array}$ & 1820 & 56,3 & 78,4 & 68,7 & 72,1 & 78,5 & 70,8 \\
\hline $\begin{array}{l}\text { Financially } \\
\text { illiterate }\end{array}$ & 4022 & 11,2 & 17,5 & 17,3 & 16,8 & 12,2 & 15,0 \\
\hline Total: & 5842 & - & - & - & - & - & 42,9 \\
\hline
\end{tabular}

Clustering was based on an assessment based on the principle of a simple majority of correct answers - financially literate and financially illiterate respondents. As a basis for assessing financial literacy, the authors adopted a questionnaire recommended by the OECD, previously adapted for Russian conditions. The data presented in Table 2 reflect the results of a two-stage survey conducted in September-November 2020 with the aim of identifying or refuting the existence of a connection between the subjective assessment of the optimal 
financial resources of households and the level of financial literacy of the population of the Sverdlovsk region.

The survey was conducted in large cities-regional centres of the Sverdlovsk region, where an approximately comparable number of respondents were interviewed: Berezovsky (618 people), Bogdanovich (558 people), Verkhnyaya Pyshma (761 people), Yekaterinburg (947 people), Irbit (610 people), Kamensk Uralsky (745 people), Nizhniy Tagil (846 people), Pervouralsk (757 people).

The survey questionnaires included five questions on financial literacy and on the assessment of the optimal financial resources of the respondents. The type of questions is closed, suggesting the possibility of subsequent assessment «right» / «wrong» for both groups of questions. The answers were recorded by respondents in the questionnaires independently. Table 3 and Figure 1 show the survey results.

Table 3. Results of the survey assessing the optimality of the structure of financial resources

\begin{tabular}{|c|c|c|c|c|c|c|c|}
\hline $\begin{array}{c}\text { Города / } \\
\text { Результат }\end{array}$ & $\begin{array}{c}\text { Number } \\
\text { people }\end{array}$ & 1 & 2 & 3 & 4 & 5 & $\begin{array}{c}\text { Average } \\
\text { means, \% }\end{array}$ \\
\hline Berezovsky & 618 & $\begin{array}{c}53,6 / \\
13,1\end{array}$ & $\begin{array}{c}78,1 / \\
19,2\end{array}$ & $\begin{array}{c}66,6 / \\
18,9\end{array}$ & $\begin{array}{c}74,2 / \\
18,8\end{array}$ & $\begin{array}{c}79,8 / \\
12,3\end{array}$ & $71 / 16,5$ \\
\hline Bogdanovich & 558 & $\begin{array}{c}52,9 / \\
8,2 \\
\end{array}$ & $\begin{array}{c}74,8 / \\
15,7 \\
\end{array}$ & $\begin{array}{c}62,4 / \\
14,4 \\
\end{array}$ & $\begin{array}{c}70,7 / \\
15,6 \\
\end{array}$ & $\begin{array}{c}76,7 / \\
10,8 \\
\end{array}$ & $67,5 / 12,9$ \\
\hline $\begin{array}{l}\text { Verkhnyaya } \\
\text { Pyshma }\end{array}$ & 761 & $\begin{array}{c}55,8 / \\
11,4\end{array}$ & $\begin{array}{c}78,5 / \\
18,1\end{array}$ & $\begin{array}{c}69,7 / \\
18,2\end{array}$ & $\begin{array}{c}68,5 / \\
17,8\end{array}$ & $\begin{array}{c}80,3 / \\
14,3\end{array}$ & $70,6 / 15,9$ \\
\hline Yekaterinburg & 947 & $\begin{array}{c}61,2 / \\
12,5\end{array}$ & $\begin{array}{c}81,8 / \\
17,1\end{array}$ & $\begin{array}{c}78,6 / \\
16,5\end{array}$ & $\begin{array}{c}74,6 / \\
15,1\end{array}$ & $\begin{array}{c}85,8 / \\
12,1\end{array}$ & $76,4 / 14,7$ \\
\hline Irbit & 610 & $\begin{array}{c}53,6 / \\
9,8\end{array}$ & $\begin{array}{c}74,6 / \\
14,4\end{array}$ & $\begin{array}{c}62,8 / \\
15,1\end{array}$ & $\begin{array}{c}68,9 / \\
14,8\end{array}$ & $\begin{array}{c}67,8 / \\
10,5\end{array}$ & $65,5 / 12,9$ \\
\hline $\begin{array}{l}\text { Kamensk } \\
\text { Uralsky }\end{array}$ & 745 & $\begin{array}{c}56,7 / \\
11,6\end{array}$ & $\begin{array}{c}78,8 / \\
17,8\end{array}$ & $\begin{array}{c}68,9 / \\
17,7\end{array}$ & $\begin{array}{c}73,3 / \\
17,2\end{array}$ & $\begin{array}{c}78,7 / \\
12,6\end{array}$ & $71,3 / 15,4$ \\
\hline Nizhniy Tagil & 846 & $\begin{array}{c}57,9 / \\
10,8\end{array}$ & $\begin{array}{c}79,9 / \\
18,3\end{array}$ & $\begin{array}{c}70,2 / \\
18,8\end{array}$ & $\begin{array}{c}73,4 / \\
17,7\end{array}$ & $\begin{array}{c}78,8 / \\
12,8\end{array}$ & $\begin{array}{c}72,04 / \\
15,7\end{array}$ \\
\hline Pervouralsk & 757 & $\begin{array}{c}58,7 / \\
12,2 \\
\end{array}$ & $\begin{array}{c}80,8 / \\
19,4 \\
\end{array}$ & $\begin{array}{c}70,4 / \\
18,8\end{array}$ & $\begin{array}{c}73,2 / \\
17,5\end{array}$ & $\begin{array}{c}80,4 / \\
12,2\end{array}$ & $\begin{array}{l}72,7 / \\
16,02\end{array}$ \\
\hline Total: & 5842 & - & - & - & - & - & - \\
\hline
\end{tabular}

The results obtained in the course of processing the data collected during the study are shown in Figure 1. In the context of cities, the results of two stages of the survey are shown at once:

- the respondents are divided into financially literate and financially illiterate according to the results of a questionnaire survey using the author's methodology, compiled on the basis of the methodology for assessing the level of financial literacy of the Central Bank of the Russian Federation;

- a survey was conducted on subjective assessment of the optimality of the structure of financial resources of all respondents.

Thus, financially literate residents of Berezovsky mostly attribute budget balance, the presence of savings and the absence of debts to these features (question 2, table 1); the presence of diversified income, accounting and planning of income and expenses (question 4) and do not apply for assistance from the state and the employer in unfavourable financial conditions. Financially illiterate residents of Berezovsky, apart from signs 2 and 4, single out 
the structural component of financial resources (question 3, table 1), but at the same time they believe that in case of financial difficulties they can count on help from outside. The average results show that financially literate respondents in Yekaterinburg, Kamensk Uralskiy, Nizhniy Tagil and Pervouralsk are more inclined to assess the optimality of their financial resources structure according to the proposed criteria than those who are not financially literate. Of the latter group (Table 3), residents of Bogdanovich and Irbit do not believe that regular monitoring of financial resources is necessary to assess the optimality: only 8.2 and $9.8 \%$, respectively, answered positively about this need. In the same cities, financially illiterate respondents count on external assistance in case of financial difficulties -89.2 and $89.5 \%$, respectively (Table 3 ). The smallest number of financially paternalistic illiterate respondents is in Verkhnyaya Pyshma (85.5\%); Nizhny Tagil (87.2\%) and Kamensk Uralsky $(87.4 \%)$. The significance of the results obtained is as follows: a significantly larger number of financially literate respondents answered correctly the questions about the criteria for optimality of the structure of financial resources (average value 70.8), while among financially illiterate respondents there are significantly fewer correct answers (average value $15 \%$ ). This means that financially literate people are capable of making informed decisions regarding the formation and management of their financial resources; this category of people is more adaptable to negative shocks of the external environment, applies planning in relation to their expenses, uses investment and savings instruments to form financial reserves.

For a full analysis of the obtained results and interpretation, it would be necessary to supplement the study with official statistics on the financial condition of the population in the cities of the Sverdlovsk region under study (Table 5). The data were selected by the authors based on the purpose of the study - to check the existence of a relationship between the level of financial literacy and the optimal structure of financial resources of households, both by subjective assessment and by objective data (Table 4).

Table 4. Indicators of the financial condition of the households in the cities of the Sverdlovsk region [12]

\begin{tabular}{|l|c|c|c|}
\hline Cities / Indicators & $\begin{array}{c}\text { Availability of } \\
\text { loans, \% }\end{array}$ & $\begin{array}{c}\text { Share of income used to } \\
\text { service debt obligations, } \\
\%\end{array}$ & Savings, \% \\
\hline Berezovsky & 71,3 & 40,1 & 13,1 \\
\hline Bogdanovich & 74,2 & 44,3 & 7,7 \\
\hline $\begin{array}{l}\text { Verkhnyaya } \\
\text { Pyshma }\end{array}$ & 75,1 & 41,4 & 11,2 \\
\hline Yekaterinburg & 82,4 & 42,7 & 12,2 \\
\hline Irbit & 78,4 & 38,3 & 5,7 \\
\hline Kamensk Uralsky & 76,5 & 43,7 & 6,9 \\
\hline Nizhniy Tagil & 81,3 & 45,1 & 7,1 \\
\hline Pervouralsk & $\mathbf{7 8 , 6}$ & 41,2 & 8,8 \\
\hline Average mean: & $\mathbf{7 7 , 2 2}$ & $\mathbf{4 1 , 7 5}$ & $\mathbf{9 , 1}$ \\
\hline
\end{tabular}

Statistical data (Table 4) do not allow analysing the financial condition of the population for the selected groups - financially literate and non-literate respondents. Moreover, there is no certainty that when approximating and averaging, it was the respondents who were surveyed that got into the statistics and the data reflect the financial condition of these people.

Nevertheless, the usefulness of the analysis of statistics is to compare the objective financial parameters of households and the perceptions in the field of financial knowledge 
that the respondents demonstrate. Obvious discrepancies on, say, the issue of a negative attitude towards loans and the correct positioning of risks associated with a credit burden with reality - the share of those who have loans from $71 \%$ in Berezovsky to 81 and $82 \%$ in Yekaterinburg and Nizhny Tagil, respectively, allow us to draw two conclusions:

- if $81.8 \%$ of financially literate respondents in Yekaterinburg believe that a loan poses a threat to their financial situation (Table 3), upsetting the balance of financial resources, but $82 \%$ of the population have loans and $42 \%$ of their income is used to finance debt obligations (Table 4), then the samples of respondents and statistically investigated do not coincide;

- people know the signs of correctness in making financial decisions, adequately talk about the need to structure their financial resources, but in practice they do not follow this.

From the first it follows that more people need to be interviewed, but even so there is no guarantee that the samples will coincide. At the same time, the use of approximation inevitably distorts the results: it can be assumed, and theoretically it is permissible, that the respondents who turned out to be financially literate fall into the category of those who do not have loans and even have savings - this is from 39 to $18 \%$ and from 7.7 to $12.2 \%$, respectively. This assumption is quite viable, as is the explanation for the second conclusion about the discrepancy in understanding and behaviour. Taking into account the inevitability of the influence of psychological factors on all spheres of behavioural manifestations, the authors believe that the discrepancy between conscious attitudes and behavioural manifestations can be caused either by subconscious opportunism, or by conscious resistance to following objectively correct norms. In the first case, people are faced with unexpected for themselves consequences of implemented decisions made under the influence of the situation, the behaviour of representatives of a representative group or information cascades. When analysing the causes of behaviour, people tend to regret, and if possible - levelling the consequences: refusal of an expensive trip «for the company», returning a purchase to a store, cancelling an order or reservation, and others.

A deliberate violation of those principles that people know about and which they consider to be correct can be dictated by weaknesses, the desire to afford more, the desire to overcome stress by buying an unusual good, the search for evidence that the desired level of consumption is achievable, or simply incontinence. All these manifestations are not pathological; they are completely safe if dispersed over time - that is, they do not pose a potential threat to the financial well-being of the households. The nature of such «deviations» from the rules is akin to the crossing of the road to a red traffic light when there are no cars on the roadway - objectively, this is a deliberate violation of traffic rules, this is not the right thing to do, because everyone knows about the transition to a green light. People, in the case of deliberately not following the correct attitudes, take on that measure of responsibility for the risk for which they must be prepared.

The key findings of this study are:

- conducting a ranking of respondents for financially literate and financially illiterate based on the processed survey results;

- assessing the opinions of the respondents of the indicated groups on the criteria for the optimality of the structure of financial resources of households;

- obtaining a substantiation of the hypothesis about the existence of a connection between the

- level of financial literacy of the population and the optimal structure of household expenditures based on the subjective opinion of the respondents;

presentation of the author's principles and criteria for the optimality of the structure of financial resources of households.

The study has the following features:

- the criteria for the optimality of the structure of financial resources proposed in the questionnaire are the author's development, clothed in an accessible conceptual and lexical form; 
- the lack of data allowing to objectively assess the state of the financial resources of the respondents who took part in the survey, therefore the authors use the term "subjective" in relation to the opinions of the sample;

- the complexity of the interpretation of some of the results, in particular: the criteria for the optimality of the structure of financial resources of the households are grouped into several questions, so the assessment of correctness depends on the number of criteria noted. The authors proceeded from the fact that the simple majority of the noted criteria is a basis for assessing «correctly». Objections in this case are appropriate from the standpoint of the significance of each individual criterion: they are not equivalent - some of them are more significant, others are less significant in relation to the purpose of the study. So, questions 2 and 3 (table 1) are focused on identifying ideas about the optimality of the structure of financial resources of the households with varying degrees of detailing of this structure; - despite the fact that the survey is a study that reveals public opinion that is not subjective, the authors tend to believe that the element of subjectivity of respondents is still present, since, firstly (noted above) it is not possible to check whether those respondents are really, which correctly indicate the criteria of optimality in relation to their financial resources, have, for example, a balanced budget are not debt. Secondly, the personal orientation of the questions and their interpretation by the respondents with the inevitable projection «on themselves». In any personal matters, and even more so concerning money and the assessment of their financial behaviour, people feel awkward and answer a lie, which reflects not reality, but their desired state of affairs. If traditional polls investigate opinion in the key: «How do you feel about such and such a politician?», or: «How do you assess the feasibility of financing the construction of a monument to someone?» The result is an array of opinions that form a public position in relation to a well-known event or person. In this study, the attitude of each respondent to those things that constitute an individual value is important their personal financial resources, and not the budget of a country or region. It is this value of opinions that presents a dilemma: should the results obtained be considered public opinion or the sum of subjective opinions? Indeed, who can openly admit that they are poor if two family members are working? - the dissonance that people try to hide behind a lie - they will refer themselves to such an attractive «middle class», realizing that they do not belong to it.

\section{The discussion of the results}

It is for reasons of supplementing the study with objectivity that the authors included a statistical array designed to show whether people follow the rules that they themselves considered correct during the survey [1]. The following aspect is debatable in this case: the statistical array averages the situation, therefore it is quite possible that those who took part in the survey were not included in the presented statistics - these results are simply approximated for everyone, including the survey respondents. Does this circumstance distort the picture obtained? - the authors believe that no, simply because there are no other options: it is extremely difficult, even theoretically, to assume that the surveyed sample of respondents is also a statistical one [4]. This is possible only under the conditions of an expensive experiment conducted in a limited time, provided that the researchers have complete and reliable information about the financial resources of the subjects and do not anonymously assess their opinions on the issue under study.

\section{Conclusion}

Nevertheless, it goes without saying that the presented results should be considered intermediate. Continuation of research in the direction of the formation of factors, criteria 
and parameters of the optimality of the structure of financial resources of households can be based on the following main hypotheses:

- does people's awareness of responsibility for pension, medical, social security, regardless of the situation in the system of state social guarantees, affect the structure of their financial resources;

- does the assessment by people of their creditworthiness affect their avoidance of debt load and bankruptcy;

- does people's perception of correct financial behaviour affect their recognition of signs of abuse of trust and unfair practices in financial transactions (pyramid schemes, etc.);

- does the level of education and the availability of assets affect the structure of their financial resources;

- whether the level of financial resource absorption and user practices affect the structure of household financial resources.

\section{Gratitude}

The publication was prepared within the framework of a Grant in the form of a subsidy from the Federal State Budgetary Educational Institution of Higher Education «Ural State University of Economics» for the implementation of the functions of a regional center of financial literacy (Agreement with the Ministry of Finance of the Sverdlovsk Region dated April 13, 2020 No. 1)

\section{References}

1. D. Brounen, G. Kees, R. Koedijk, A.J. Rachel, Journal of International Money and Finance, 69 (2016)

2. A. Cardaci, Journal of Economic Behavior \& Organization, 149 (2018)

3. S. Drews, M. Antal, C. Jeroen, M. van den Bergh, Ecological Economics, 146 (2018)

4. D. French, S. Vigne, International Review of Financial Analysis, 62 (2019)

5. Halilovic S., Zaimovic A., Arnaut Berilo A., Zaimovic T. Financial Literacy Assessment in Bosnia and Herzegovina // Procedia Computer Science, Volume 158, (2019)

6. J. Zou, X. Deng. China Economic Review, 55 (2019)

7. L.S. Lopus, D.S. Amidjono, P.W. Grimes, International Review of Economics Education, 32 (2019)

8. E.A. Razumovskaya, D.U. Razumovsky, Advances in Economics, Business and Management Research, 138(2) (2020)

9. J.J. Reade, L.V. Williams, International Journal of Forecasting, 35, 1 (2019)

10. The official website of the Analytical center NAFR, https://nafi.ru/analytics/

11. The official website of the Central Bank of the Russian Federation , https://www.cbr.ru/Ankets/MailForm.aspx?PartID=fingram

12. The official website of the Federal State Statistics Service of the Russian Federation, www.rgs.ru 